\title{
Pengaruh Gaya Kepemimpinan Transformasional dan Tranksaksional Terhadap Kinerja Sistem Jaminan Halal HAS 23000
}

\author{
Evy Yanthy', Agus Purwanto², Rudy Pramono³, Yoyok Cahyono4, \\ Masduki Asbari ${ }^{5}$ \\ Universitas Pelita Harapan1, Universitas Pelita Harapan², Universitas \\ Pelita Harapan ${ }^{3}$, Universitas Pramita Indonesia ${ }^{4}$, Universitas Pelita \\ Harapan 5 \\ evyyanthy2019@gmail.com ${ }^{1}$, agozpor@gmail.com ${ }^{2}$, \\ rudy.pramono@uph.edu ${ }^{3}$,yoyok.unpri@gmail.com ${ }^{4}$, \\ kangmasduki.sii@gmail.com ${ }^{5}$
}

\begin{abstract}
This study aims at explaining the effect of transformational and transactional leadership styles on the performance of the HAS 23000 Halal Assurance System implementation in the food industry in Tangerang. The respondents of the study was 200 employees in several food industries that were located in the Tangerang who had implement the HAS 23000 Halal Assurance System. Data was collected by giving online electronic questionnaires to- employees randomly. This study provides results that show that transformational leadership style has a positive and significant effect on the performance of the HAS 23000 Halal Assurance System implementation and the transactional leadership style is also positive affects the performance of the HAS 23000. This study concluded that leadership is important in the performance of the HAS Halal Assurance System implementation HAS 23000.

Keywords: Transformational Leadership, Transactional, Halal Assurance System HAS 23000
\end{abstract}

\begin{abstract}
Abstrak
Penelitian ini bertujuan untuk melihat analisis dari gaya kepemimpinan transformasional dan transaksional serta pengaruhnya terhadap kinerja penerapan Sistem Jaminan Halal HAS 23000 pada industri makanan di Tangerang. Obyek dari penelitian adalah karyawan di beberapa industri makanan yang berkolasi di wilayah Kota Tangerang yang telah menerapkan Sistem Jaminan Halal HAS 23000 sebanyak 200 orang dan metode pengumpulan data dengan memberikan kuesioner elektronik kepada beberapa karyawan secara acak. Alat analisis yang digunakan dalam penelitian ini adalah SEM (Structural Equation Model) pada program LISREL versi 8.70. Penelitian ini memberikan hasil yang menunjukkan bahwa gaya kepemimpinan transformasional terbukti berpengaruh positif dan signifikan terhadap kinerja penerapan Sistem Jaminan Halal HAS 23000dan gaya kepemimpinan transaksional juga positif dan mempengaruhi kinerja penerapan Sistem Jaminan Halal HAS 23000dan disimpulkan bahwa kepemimpinan merupakan hal penting dalam kinerja penerapan Sistem Jaminan Halal HAS 23000

Kata Kunci: Kepemimpinan Transformasional, Transaksional, Sistem Jaminan Halal HAS 23000
\end{abstract}




\section{PENDAHULUAN}

Kewajiban sertifikasi halal sesuai dengan UU JPH mulai dilaksanakan tanggal 17 Oktober 2019 dan proses sertifikasi diperuntukkan untuk makanan dan minuman terlebih dahulu selanjutnya ditujukan untul produk kosmetik, obat, dan alat medis. Pemerintah telah melaksanakan tugasnya dalam memberi jaminan halal kepada warganya. Pelaku usaha juga dapat memperluas target pasarnya, meningkatkan daya saing, meningkatkan omset produksi dan penjualan, serta meningkatkan kepercayaan konsumen terhadap kehalalan produk. Disamping itu, masyarakat muslim juga akan lebih merasa tenang dalam membeli dan mengonsumsi produk berlabel halal (Pelu 2009).

Pada era industri 4.0 ini tingkat persaingan industri semakin ketat terutama industri makanan dan minuman dan supaya dapat mempertahankan kelangsungan hidup perusahaan diperlukan kinerja yang tinggi dari keseluruhan sumberdaya manusianya. Penerapan sistem Sistem Jaminan Halal HAS 23000 pada industri makanan menjamin produk yang dihasilkan aman dan akan meningkatkan daya saing perusahaan di pasaran global (Segovia et al, 2014). Beberapa perusahaan produsen makanan menerapkan Sistem Jaminan Halal HAS 23000 untuk meningkatkan efisiensi, produktivitas serta kualitas produknya dan banyak perusahaan tidak menyadari potensi manfaat penerapannya dan merasakan biaya tinggi yang terkait implementasi (Maria et al, 2014). Hambatan utama untuk implementasi Sistem Jaminan Halal HAS 23000 pada umumnya kurangnya sumber daya keuangan, ukuran organisasi, infrastruktur dan fasilitas yang tidak memadai, dan kurangnya komitmen manajemen puncak. Motivasi utama untuk implementasi FSSC 22000 adalah untuk meningkatkan kualitas dan keamanan produk serta peningkatan keterampilan karyawan, peningkatan citra perusahaan, peningkatan penjualan produk, peningkatan pangsa pasar, dan akses ke pasar baru (ISO.org, 2018). Pada Sistem Jaminan Halal HAS 23000 disyaratkan pentingnya kepemimpinan dan komitmen dari top manajemen agar implementasinya bisa berjalan dengan baik, manajemen puncak harus menunjukkan kepemimpinan dan komitmen, menetapkan, menerapkan, dan memelihara kebijakan keamanan pangan ( Dwiantoro et al, 2014)

Penelitian ini di perusahaan industri yang bergerak dibidang makanan kemasan yang berlokasi di Tangerang dan telah menerapkan Sistem Jaminan Halal HAS 23000 selama 2 tahun sebagai komitmen perusahaan untuk menjaga kualitas produknya. Saat ini memiliki kendala belum optimalnya penerapan Sistem Jaminan Halal HAS 23000 yang terlihat dari setiap pelaksanaan internal audit masih banyak temuan.Pada tahun 2018 ada 8 temuan major dan 34 temuan minor sedangkan pada tahun 2019 ada 8 temun major dan 45 temuan minor. Temuan-temuan ini mengindikasikan bahwa penerapan Sistem Jaminan Halal HAS 23000 belum berjalan dengan baik. Menurut keterangan beberapa karyawan bahwa salah satu dugaan penyebab belum optimalnya penerapan Sistem Jaminan Halal HAS 23000 karena keterlibatan pimpinan puncak dan menengah yang belum optimal. 
Dengan demikian penelitian ini bertujuan untuk mengetahui bagaimana kepemimpinan transformasional dan kepemimpinan transaksional dapat mempengaruhi kinerja penerapan Sistem Jaminan Halal HAS 23000. Beberapa penelitian terdahulu telah membahas pengaruh kepemimpinan terhadap kinerja secara umum dan penelitian ini akan membahas lebih spesifik yaitu kinerja penerapan Sistem Jaminan Halal HAS 23000. Penelitian ini memiliki tujuan untuk membuat analisis terhadap pengaruh kepemimpinan transformasional dan pengaruh kepemimpinan transaksional terhadap kinerja penerapan Sistem Jaminan Halal HAS 23000.

\section{KAJIAN LITERATUR \\ Gaya Kepemimpinan}

Kepemimpinan adalah pengaruh sosial proses di mana pemimpin mencari sukarela partisipasi bawahan dalam upaya mencapai mengorganisasi tujuan (Omolayo, 2007). Seorang pemimpin dapat didefinisikan sebagai pribadi yang mendelegasikan atau memengaruhi orang lain untuk bertindak sehingga dapat dilakukan tujuan yang ditentukan (Mullins, 2004). Organisasi hari ini perlu pemimpin yang efektif yang memahami kompleksitas dari yang cepat perubahan lingkungan global. Jika tugasnya sangat terstruktur dan pemimpin memiliki hubungan yang baik dengan karyawan, efektivitas akan tinggi pada bagian dari para karyawan. Penelitian lebih lanjut mengungkapkan para pemimpin sangat berhati-hati untuk melibatkan semua anggota tim dalam diskusi dan dapat bekerja dengan yang kecil tapi sangat tim termotivasi. Barchiesi et all.(2007) mengukur efektivitas kepemimpinan dan peran kepemimpinan dan pengaruhnya terhadap kinerja, kepemimpinan perilaku, sikap. Mereka menemukan kepemimpinan yang tinggi indeks tidak terkait dengan catatan kinerja masa lalu tetapi terkait baik dengan potensi peningkatan yang lebih tinggi kinerja dan untuk reputasi organisasi yang lebih tinggi, menunjuk ke arah pengaruh yang berarti kompleksitas perilaku dan dinamika pada kepemimpinan tingkat yang dirasakan. Mekanisme gaya kepemimpinan mempengaruhi Tim berinovasi di pusat-pusat penelitian swasta diselidiki hubungan antara gaya kepemimpinan yang berbeda dan tim berinovasi dengan efek mediasi pengetahuan berbagi dan komunikasi tim ( Wang et al,2007). Voon et al.(2011) menemukan pengaruh gaya kepemimpinan merupakan bagian dari organisasi sektor publik di Malaysia. Mereka menggunakan faktor-faktor seperti gaji, pekerjaan otonomi, keamanan kerja, fleksibilitas tempat kerja. Dari semua ini faktor, mereka menemukan gaya kepemimpinan transformasional memiliki hubungan yang lebih kuat dengan kepuasan kerja.

Chung et al.( 2008) mengidentifikasi gaya kepemimpinan itu dapat mempengaruhi komitmen organisasi dan kepuasan kerja positif dan kepuasan kerja magang dapat mempengaruhi komitmen organisasi dan kinerja kerja secara positif. Kepemimpinan sebagian besar berorientasi pada budaya, merangkul kepercayaan, norma dan nilai-nilai tradisional . Menurut penelitian Goh Yuan et al.(2005) gaya kepemimpinan secara signifikan 
dipengaruhi oleh pemimpin keluarga dekat, keluarga, klan dan suku. Pelajaran ini menemukan hubungan antara kepemimpinan organisasi dan etika bisnis, dengan demikian memberikan kontribusi meningkatkan kualitas kehidupan organisasi yang mungkin memiliki pengaruh positif pada kedua anggota organisasi dan masyarakat luas.

Lu Ye et al.(2007) belajar menjelaskan persepsi karyawan tentang transaksi atau gaya kepemimpinan transformasional eksekutif, keduanya miliki korelat sangat positif dengan persepsi tentang faktor dorongan eksekutif dari inovasi iklim. Podsakoff et al.(1990) mengatakan bahwa perilaku kepemimpinan dapat mempengaruhi kepercayaan dan kepuasan karyawan terhadap organisasi dan perilaku organisasi lebih meningkatkan lagi hubungan antara gaya kepemimpinan dan organisasi komitmen secara langsung. Kepemimpinan transaksional dianggap sebagai imbalan bawahan melalui mereka upaya dan kinerja. Guang-yi et al.(2008) membandingkan Kepemimpinan transaksional. Kepemimpinan transformasional dianggap meningkatkan kinerja bawahan dengan mengubah motif dan nilai-nilai karyawan. Bass (1997) membagi gaya kepemimpinan menjadi transformasional kepemimpinan dan kepemimpinan transaksional. Kepemimpinan transformasional memiliki karakteristik pengaruh individu, dorongan spiritual dan peniruan intelektual. Mereka sering mempertimbangkan individu, membangun visi dan membidik ke dalam, menciptakan budaya terbuka, memercayai staf untuk mencapainya tujuan mereka dan memberikan permainan penuh untuk potensi staf.

\section{Gaya kepemimpinan Transformasional}

Gaya kepemimpinan berkonsentrasi pada pengembangan pengikut serta kebutuhan mereka. Manajer dengan gaya kepemimpinan transformasional berkonsentrasi pada pertumbuhan dan pengembangan sistem nilai karyawan, (Ismail, 2009). Menurut Bass (2005), tujuan transformasional kepemimpinan adalah untuk 'mentransformasi' orang dan mengatur ion dalam arti harfiah - untuk mengubahnya di Internet pikiran dan hati memperbesar visi, wawasan dan pengertian memperjelas alasan membuat perilaku kongruen dengan nilai-nilai, konsep dan membawa perubahan yang permanen, mengabadikan diri dan membangun momentum. Menurut Bass (2005) kepemimpinan transformasional terjadi ketika pemimpin menjadi lebih luas dan menjunjung tinggi kepentingan karyawan, begitu mereka menghasilkan kesadaran dan penerimaan untuk tujuan dan penugasan kelompok, jadi ketika mereka membaurkan karyawan untuk muncul di luar kepentingan diri mereka sendiri demi kebaikan kelompok. Menurut Bass \& Avolio (2005) pemimpin transformasional dorong pengikut untuk melihat masalah dari yang baru perspektif, memberikan dukungan dan dorongan mengkomunikasikan visi, merangsang emosi dan ion identifikasi. Bruce et al (1995) mengatakan itu pemimpin transformasional dapat mendefinisikan dan mengartikulasikan visi untuk mereka Organisasi dan gaya kepemimpinan mereka dapat mempengaruhi atau mentransformasikan 
variabel tingkat individu seperti peningkatan memotivasi ion dan mengatur tingkat ion, seperti menengahi konflik di antara kelompok atau tim. Podsakoff et al (1990) diungkapkan kepemimpinan transformasional telah aktif pengaruh pada hasil individu dan organisasi tersebutsebagai faksi dan kinerja karyawan. Tingkat lebih tinggi kepemimpinan transformasional dikaitkan dengan yang lebih tinggi tingkat potensi kelompok.

\section{Gaya Kepemimpinan Transaksional}

Kepemimpinan transaksional lebih bergantung pada "perdagangan" antara pemimpin dan pengikut dimana pengikut dikompensasi untuk pertemuan khusus tujuan atau kriteria kinerja (Sharma, 1987). Pemimpin transaksional pertama akan memvalidasi hubungan antara kinerja dan hadiah dan kemudian menukarnya dengan respons yang sesuai yang mendorong bawahan untuk meningkatkan kinerja (Jung, 2001). Kepemimpinan transaksional dalam organisasi memainkan peranan penting pertukaran peran antara manajer dan bawahan (Jung, 2001). Gaya kepemimpinan transaksional dipahami sebagai pertukaran imbalan dan target antara karyawan dan manajemen ( Howell,1993). Bass \& Avolio (1990) menjelaskan pemimpin transaksional memotivasi bawahan melalui penggunaan kontingen penghargaan, tindakan korektif dan penegakan aturan. Bass (1990) menjelaskan kepemimpinan transaksional itu tergantung pada penguatan kontingen, baik positif hadiah kontingen atau lebih negatif aktif atau pasif bentuk manajemen-oleh-pengecualian. Pemimpin transaksional memotivasi pengikut melalui pertukaran; sebagai contoh,menyelesaikan pekerjaan dengan imbalan hadiah atau preferensi (Yang, 2007). Kahai et al.(1997) menemukan kemanjuran kelompok lebih tinggi di bawah kepemimpinan kondisi transaksional. Pemimpin transaksional cenderung fokus pada tugas penyelesaian dan kepatuhan karyawan serta para pemimpin ini sangat bergantung pada imbalan organisasi dan hukuman untuk mempengaruhi kinerja karyawan.

\section{Sistem Jaminan Halal (HAS)}

Sistem Jaminan Halal diperkenalkan oleh Lembaga Pengkajian Pangan dan Obat-obatan Kosmetika Majelis Ulama Indonesia (LPPOM MUI) sejak 2005, sebagai suatu sistem untuk memastikan kehalalan produk selama validitas Sertifikasi Halal MUI. Untuk mendukung perusahaan untuk memahami dan mengimplementasikan sistem, LPPOM MUI telah menerbitkan Pedoman Umum Sistem Jaminan Halal. Pengaturan dan implementasi HAS oleh perusahaan harus sejalan dengan internal operasi. Setiap produsen harus memenuhi kebutuhan dan hak konsumen, termasuk konsumen muslim. Memproduksi produk halal adalah bagian dari tanggung jawab perusahaan kepada konsumen muslim. Di Indonesia, untuk meyakinkan konsumen bahwa produknya halal, perusahaan perlu memiliki sertifikat halal MUI.

Keuntungan menerapkan Sistem Jaminan Halal adalah Perusahaan akan memiliki panduan dalam menjaga keberlanjutan produksi halal proses, 
memastikan kehalalan produk dalam masa berlaku Sertifikat Halal MUI, memberikan jaminan dan ketenangan spiritual bagi asyarakat muslim, mencegah dari setiap kasus yang terkait dengan ketidaksesuaian yang menyebabkan ketidakhalusan produk, melindungi dari segala kasus ketidakhalusan yang dapat menyebabkan kerugian perusahaan, meningkatkan loyalitas konsumen terhadap kehalalan produk, menciptakan kesadaran halal internal di perusahaan untuk menjaga keberlanjutan produksi halal, Penghargaan dari konsumen (kepuasan pelanggan) dan lembaga eksternal.

\section{METODE PENELITIAN}

\section{Rancangan Penelitian dan Hipotesis}

Berdasarkan hasil dari pemaparan penelitian - penelitian terdahulu maka diperoleh kerangka konsep rancangan penelitian sebagai berikut :

\section{Gambar 1 Kerangka Konsep Penelitian}

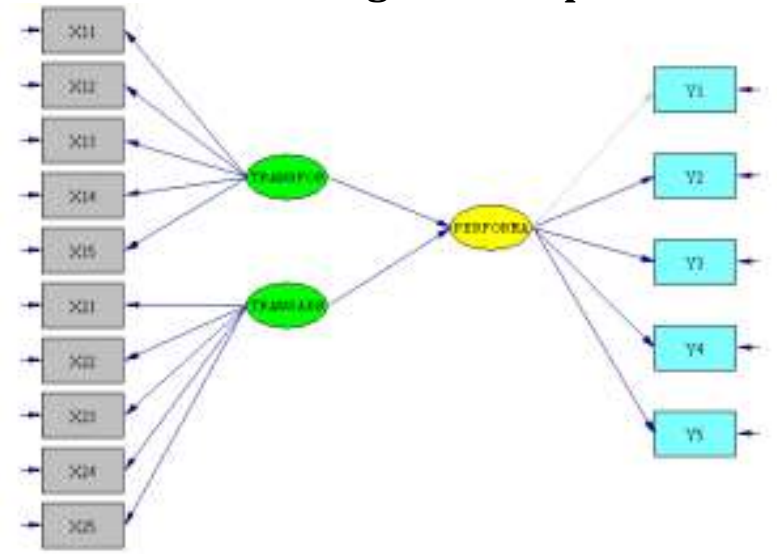

Berdasarkan konsep kerangka model penelitian diatas maka didapatkan hipotesis sebagai berikut:

1. Diduga terdapat pengaruh yang signifikan gaya kepemimpinan tipe transformasional (X1) terhadap kinerja penerapan Sistem Jaminan Halal HAS 23000 (Y).

2. Diduga terdapat pengaruh yang signifikan gaya kepemimpinan tipe transaksional (X2) terhadap kinerja penerapan Sistem Jaminan Halal HAS 23000 (Y).

Untuk hipotesis 1, variabel bebas (independent variable) adalah gaya kepemimpinan tipe transformasional (X1) sedangkan variabel tergantung (dependent variable) adalah kinerja penerapan Sistem Jaminan Halal HAS 23000 (Y). Untuk hipotesis 2, variabel bebas (independent variable) adalah gaya kepemimpinan transaksional (X2) Sedang variabel tergantung (dependent variable) adalah kinerja penerapan Sistem Jaminan Halal HAS $23000(\mathrm{Y})$. 


\section{Metode Pengumpulan Data}

Data yang diperlukan dalam penelitian ini adalah data primer dari responden. Metode pengumpulan data primer menggunakan elektronik kuesioner dan menggunakan metode pengukuran dengan skala Likert. Jawaban dari setiap pernyataan dibuat lima alternatih jawaban dan penilaian untuk setiap jawaban diberi bobot a). Tidak Pernah (TP) skor:1, b). Hampir Tidak Pernah (HTP) skor 2, c). Kadang-kadang (KK) skor 3, d). Sering (SR) skor 4 dan e). Selalu (SL) skor 5.

Indikator pada variabel kepemimpinan tipe transformasional (X1) yaitu faktor-faktor Charisma, Inspirational, Intellectual stimulation, serta Individulized consideration dengan 5 item pernyataan. Sedangkan indikatorindikator pada variabel kepemimpinan tipe transaksional, meliputi faktorfaktor contingent reward, management by-exception: (active dan passive) serta Laissez-faire. Indikator-indikator untuk variabel kinerja karyawan meliputi faktor-faktor seperti kuantitas kerja karyawan, kualitas kerja, efisiensi, usaha karyawan, standar profesional, ketepatan dan kreatifitas dengan 5 item pernyataan. Populasi dalam penelitian ini adalah semua karyawan PT. Industri makanan yang berjumlah 200 orang dan semua populasi dijadikan responden disebut metode sensus.

Tabel 1. Profil responden menurut tingkat pendidikan

\begin{tabular}{l|l|l}
\hline No & Education & Total \\
\hline 1 & SMK & 68 \\
\hline 2 & D3 & 52 \\
\hline 3 & S1 & 48 \\
\hline 4 & S2 & 32 \\
\hline Total & & 200
\end{tabular}

Sumber: Data internal yang diolah

Tabel 2. Profil responden menurut masa kerja

\begin{tabular}{l|l|l}
\hline \multirow{2}{*}{ No } & Masa Kerja & \multirow{2}{*}{ Total } \\
\cline { 2 - 3 } & ( Tahun ) & 59 \\
\hline 1 & $0-5$ & 61 \\
\hline 2 & $6-10$ & 46 \\
\hline 3 & $11-15$ & 34 \\
\hline 4 & $16-20$ & 200
\end{tabular}

Sumber: Data internal yang diolah

Tabel 3. Profil responden menurut bagian

\begin{tabular}{l|l|l}
\hline No & Bagian & Total \\
\hline 1 & Production & 62 \\
\hline 2 & Warehouse & 50 \\
\hline 3 & Quality Control & 47 \\
\hline 4 & Office & 41 \\
\hline \multicolumn{2}{l}{ Total } & 200
\end{tabular}

Sumber: Data internal yang diolah 
Berdasarkan data profil responden diatas sudah menunjukkan distribusi responden yang merata dari tingkat masa kerja, pendidikan serta bagian atau departemen tempat mereka melakukan aktivitas pekerjaan.

\section{Teknis Analisa Data}

Analisa data yang dilakukan pada penelitian ini menggunakan Structural Equation Modelling (SEM) dengan alat bantu software Linear Structural Model (LISREL). Keungulan software dengan merk Lisrel adalah kemampuannya dalam menguji hubungan antara variabel laten, serta indicator - indikatornya. Data dari nilai Validitas dan reliabilitas konstruk dari tiap indikator-indikator pada penelitian ini didapat dengan melakukan perhitungan melalui Confirmatory Factor Analysis (CFA). Validitas dan realibilitas akan diuji dengan menggunakan analisis faktor konfirmatori untuk mendapatkan data yang cukup valid dan reliabel. Second order confirmatory factor analysis (2nd Order CFA) adalah merupakan bentuk/model pengukuran yang terdiri dari dua tingkat, dengan tingkat pertama yaitu analisis dilakukan dari konstruk laten aspek ke setiap indikator-indikatornya dan yang kedua, analisis akan dilakukan dari konstruk laten ke konstruk aspeknya. Dengan CFA tidak hanya bisa dilakukan pengujian validitas konstrak (Construct Validity), tetapi juga dapat melakukan pengujian reliabilitas konstruk (Construct Reliability). Konstruk dikatakan bisa mempunyai reliabilitas yang baik adalah jika nilai Construct Reliability $(\mathrm{CR}) \geq 0,70$ dan nilai variance extracted $\geq 0,50$. ukuran konstruk reliabilitas bisa disimpulkan baik jika nilainya lebih dari 0,40 .

\section{HASIL DAN PEMBAHASAN}

Metode untuk analisis data dapat dilakukan dengan menggunakan Structural Equation Model (SEM) yaitu software Linear Structural Model (LISREL) versi 8.71 dari Joreskog dan Sorbom (2008) melalui 2nd Order CFA dengan kriteria untuk nilai loading factor $(>0.5)$ dan untuk nilai t hitung $(>1,96)$ hasilnya ditunjukkan pada gambar berikut:

\section{Gambar 2 Nilai loading factor order CFA}

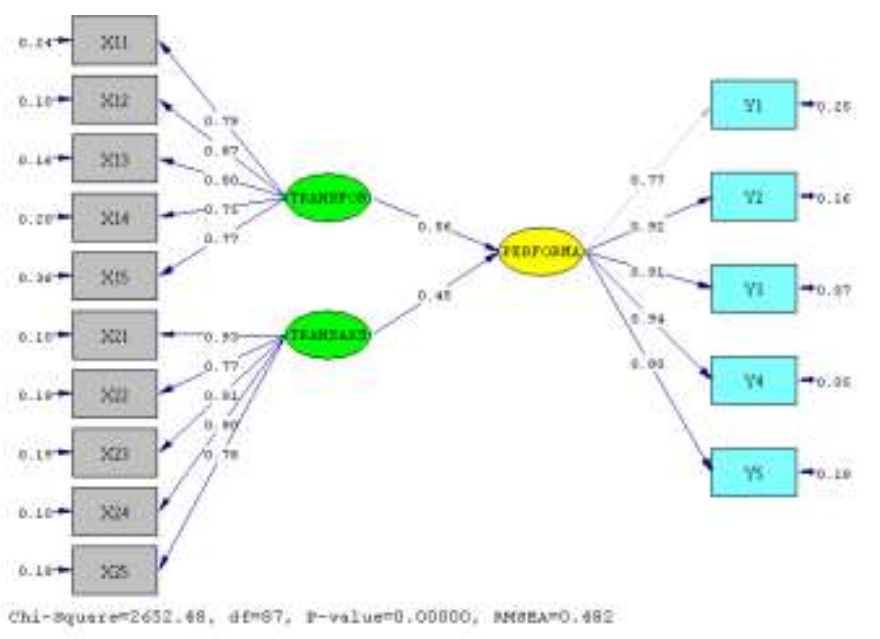




\section{Gambar 3 Nilai t order CFA}

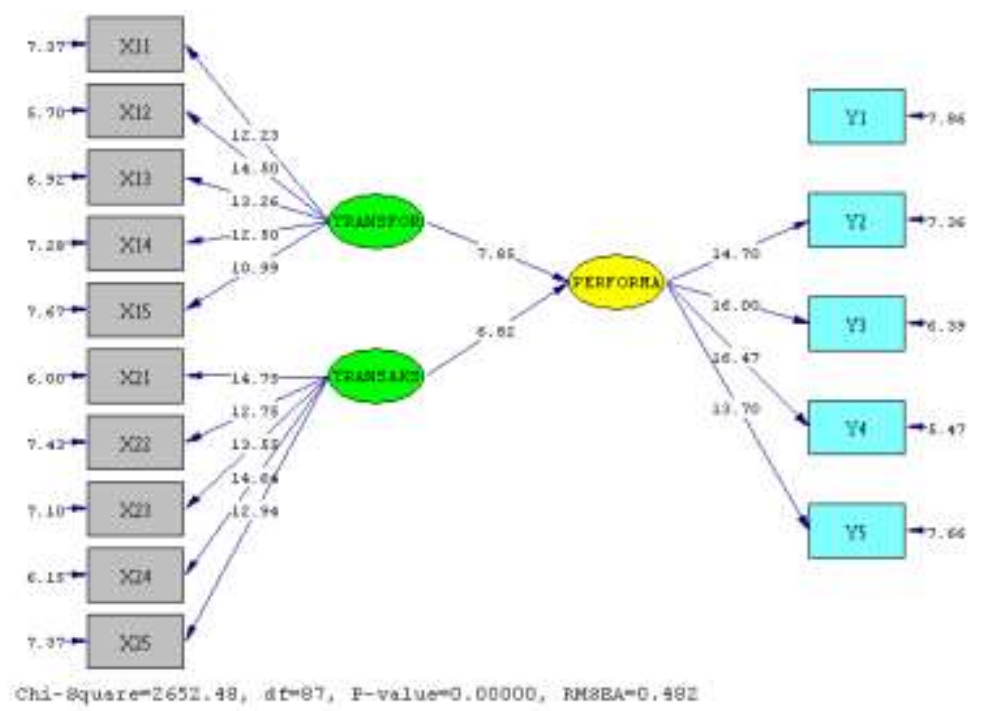

Berdasarkan dari gambar 1 dan gambar 2 dapat dilihat bahwa tidak ada nilai negative error variance, karena tidak terdapat nilai error variance yang bernilai negatif. Apabila terdapat error variance yang bernilai negatif, maka variabel teramati dalam persamaan tersebut akan dihilangkan dari model. Langkah awal dari analisis dilakukan dari konstruk laten aspek ke indikator-indikatornya. Berdasarkan hasil analisis data di atas menunjukkan bahwa nilai loading faktor semuanya diatas 0.5 ( $>0,5$ ) dan semua nilai $t$ hitung yang diperlukan untuk menguji signifikansi nilai loading faktor lebih besar dari 1,96 ( >1.96). Hal ini bahwa seluruh item valid dan signifikan. Rangkuman dari hasil analisis tersebut diatas bisa dilihat pada tabel berikut ini:

Tabel 4. Analisis Untuk 2nd Order CFA Construct Validity (Aspek-Indikator)

\begin{tabular}{l|l|l|l|l}
\hline \multirow{2}{*}{ Variable } & Item & $\begin{array}{l}\text { Loading } \\
\text { factor }\end{array}$ & T-Value & Information \\
\hline \multirow{4}{*}{$\begin{array}{l}\text { Transformational } \\
\text { leadership (X1) }\end{array}$} & $\mathrm{X} 11$ & 0.79 & 12.23 & Sig \\
\cline { 2 - 5 } & $\mathrm{X} 12$ & 0.87 & 14.50 & Sig \\
\cline { 2 - 5 } & $\mathrm{X} 13$ & 0.80 & 13.26 & Sig \\
\cline { 2 - 5 } & $\mathrm{X} 14$ & 0.75 & 12.50 & Sig \\
\cline { 2 - 5 } & $\mathrm{X} 15$ & 0.77 & 10.99 & Sig \\
\hline \multirow{4}{*}{$\begin{array}{l}\text { Transactional } \\
\text { leadership (X2) }\end{array}$} & $\mathrm{X} 21$ & 0.93 & 14.75 & Sig \\
\cline { 2 - 5 } & $\mathrm{X} 22$ & 0.77 & 12.75 & Sig \\
\cline { 2 - 5 } & $\mathrm{X} 23$ & 0.91 & 13.55 & Sig \\
\cline { 2 - 5 } & $\mathrm{X} 24$ & 0.90 & 14.64 & Sig \\
\cline { 2 - 5 } & $\mathrm{X} 25$ & 0.78 & 12.94 & Sig \\
\hline \multirow{2}{*}{$\begin{array}{l}\text { Sistem Jaminan Halal } \\
\text { Performance (Y) }\end{array}$} & $\mathrm{Y} 1$ & 0.77 & & Sig \\
\cline { 2 - 5 } & $\mathrm{Y} 2$ & 0.92 & 14.70 & \\
\end{tabular}


Sumber: Data internal yang sudah diolah

\begin{tabular}{|l|l|l|l}
\hline Y3 & 0.91 & 16.10 & Sig \\
\hline Y4 & 0.90 & 16.47 & Sig \\
\hline Y5 & 0.78 & 13.70 & Sig
\end{tabular}

Tingkat kedua analisis berikutnya dilakukan dari konstruk laten ke konstruk aspeknya. Berdasarkan dari hasil pengujian di atas didapatkan bahwa nilai dari loading faktor seluruhnya didapatkan diatas $0.5(>0,5)$ dan semua nilai t hitung yang diperlukan untuk menguji tingkat signifikansi nilai loading faktor didapatkan lebih besar dari 1,96 (>1.96). Rangkuman dari hasil analisis tersebut diatas dapat dilihat pada tabel 5.

Tabel 5.

Analisis Untuk 2nd Order CFA Construct Validity OCB (Laten-Aspek)

\begin{tabular}{l|l|l|l|l}
\hline Variable & Item & Loading factor & T-Value & Information \\
\hline $\begin{array}{l}\text { Transformational } \\
\text { leadership }\end{array}$ & $\mathrm{X} 1$ & 0.56 & 7.85 & Sig \\
\hline $\begin{array}{l}\text { Transactional } \\
\text { Leadership }\end{array}$ & $\mathrm{X} 2$ & 0.45 & 6.85 & Sig
\end{tabular}

Sumber: Data internal yang sudah diolah

Hasil tersebut dapat disimpulkan bahwa kedua aspek yang terdiri dari gaya kepemimpinan transformasional dan gaya kepemimpinan transaksional disimpulkan valid dan signifikan. Hasil dari validitas tersebut diperkuat juga dengan nilai Chi Square (r) yang menghasilkan nilai sebesar 2652.48 Berdasarkan dari rumus perhitungan konstruk reliabilitas diperoleh hasil CR sebesar 0,84 dan VE sebesar 0,73 yang disiumpulkan bahwa variabel memiliki reliabilitas yang baik. Hair (2010) menyatakan bahwa nilai konstruk mempunyai reliabilitas yang baik bila nilai Construct Reliability $(C R) \geq 0,7$ dan nilai variance extracted $(\mathrm{VE}) \geq 0,40$.

Tabel 6.

Hasil Analisis 2nd Order CFA Cunstruct Reliability OCB

\begin{tabular}{l|l|l|l|l|l}
\hline Variable & Item & $\begin{array}{l}\text { Loading } \\
\text { Factor }\end{array}$ & Error & CR & VE \\
\hline \multirow{4}{*}{$\begin{array}{l}\text { Transformational } \\
\text { leadership (X1) }\end{array}$} & $\mathrm{X} 11$ & 0.79 & 0.24 & & \\
\cline { 2 - 5 } & $\mathrm{X} 12$ & 0.87 & 0.10 & & \\
\cline { 2 - 4 } & $\mathrm{X} 13$ & 0.80 & 0.16 & & \\
\cline { 2 - 4 } & $\mathrm{X} 14$ & 0.75 & 0.20 & \multirow{4}{*}{0.84} & \multirow{2}{*}{0.73} \\
\cline { 2 - 4 } & $\mathrm{X} 15$ & 0.77 & 0.36 & & \\
\hline \multirow{3}{*}{$\begin{array}{l}\text { Transactional } \\
\text { leadership (X2) }\end{array}$} & $\mathrm{X} 21$ & 0.93 & 0.10 & & \\
\cline { 2 - 4 } & $\mathrm{X} 22$ & 0.77 & 0.19 & & \\
\cline { 2 - 4 } & $\mathrm{X} 23$ & 0.91 & 0.10 & &
\end{tabular}




\begin{tabular}{l|l|l|l|} 
& $\mathrm{X} 24$ & 0.90 & 0.18 \\
\cline { 2 - 4 } & $\mathrm{X} 25$ & 0.78 & 0.25 \\
\hline \multirow{4}{*}{ Performance (Y) } & $\mathrm{Y} 1$ & 0.77 & 0.16 \\
\cline { 2 - 4 } & $\mathrm{Y} 2$ & 0.92 & 0.07 \\
\cline { 2 - 4 } & $\mathrm{Y} 3$ & 0.91 & 0.05 \\
\cline { 2 - 4 } & $\mathrm{Y} 4$ & 0.90 & 0.10 \\
\cline { 2 - 4 } & Y5 & 0.78 & 0.10
\end{tabular}

Sumber: Data internal yang sudah diolah

Dengan demikian berdasarkan dari hasil analisis perhitungan realibilitas diatas dapat disimpulkan bahwa realibilitas pada model pengukuran adalah baik. Pengujian measurement model, telah terbukti bahwa penelitian telah memenuhi persyaratan seluruh tahapan pengujian.

\section{Analisis Goodness Of Fit (GOF)}

Uji kecocokan dari model secara keseluruhan atau secara overall model fit yang berkaitan dengan analisis terhadap nilai GOF statistik yang dihasilkan oleh program Lisrel dan hasil GOF statistik ada pada gambar 2. Untuk kesesuaian modelnya (model fit) sudah cukup baik dan untuk kriteria model fit-nya seperti pada tabel 7.

Tabel 7 Kriteria Model Fit

\begin{tabular}{l|l|l|l}
\hline Fit Index & Value & $\begin{array}{c}\text { Value } \\
\text { Standard }\end{array}$ & Information \\
\hline Chi-Square & 2652.48 & $>0.5$ & Baik \\
\hline $\begin{array}{l}\text { Root Mean Square Error of } \\
\text { Approximation (RMSEA) }\end{array}$ & 0.07 & $<0.08$ & Baik \\
\hline Normed Fit Index (NFI) & 0.99 & $>0.90$ & Baik \\
\hline Non-Normed Fit Index (NNFI) & 0.95 & $>0.90$ & Baik \\
\hline Comparative Fit Index (CFI) & 0.94 & $>0.90$ & Baik \\
\hline Incremental Fit Index (IFI) & 0.95 & $>0.90$ & Baik \\
\hline Relative Fit Index (RFI) & 0.94 & $>0.90$ & Baik
\end{tabular}

Sumber: Data internal yang sudah diolah

Berdasarkan dari hasil analisis diatas dapat diketahui bahwa sebanyak 6 dari 9 indeks fit menyatakan bahwa model fit. Hasil ini menunjukkan bahwa variabel dinyatakan valid dan reliable sehingga dapat disimpulkan bahwa kecocokan keseluruhan model masih baik. 
Evy Yanthy dkk.

Gambar 4. Structural Equations

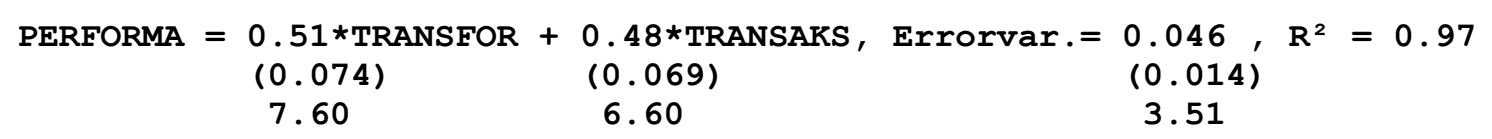

Berdasarkan hasil dari analisis diatas dapat dilihat bahwa kepemimpinan gaya transformasional berpengaruh secara positif dan signifikan terhadap kinerja sistem manajemen keamanan pangan dengan nilai t statistik yang diperoleh sebesar $7.85>1.96$ dengan koefisien unstandardized nya sebesar 0.51. Untuk kepemimpinan gaya transaksional juga berpengaruh secara positif dan signifikan terhadap kinerja sistem manajemen keamanan pangan dengan nilai $t$ statistik diperoleh sebesar $6.60>1.96$ dengan koefisien unstandarized sebesar 0.48. Goodness of fit model yang dihasikan cukup baik dengan nilai chi square 2652. Untuk kriteria goodness of fit yang lainnya juga sudah memenuhi syarat yang diperlukan. Software Lisrel sudah banyak dipakai untuk mengolah dan menganalisa data di beberapa penelitian diantaranya adalah Cavusoglu et al (2012) dan OleBoe et al.(2010).

\section{Pengaruh gaya Kepemimpinan Transformasional (X1) pada Sistem Jaminan Halal HAS 23000 (Y)}

Berdasarkan analisis disimpulkan bahwa gaya kepemimpinan transformasional berpengaruh positif dan signifikan terhadap kinerja sistem manajemen keamanan pangan dengan nilai statistik $t$ yang diperoleh sebesar 7,60> 1,96 dengan koefisien tidak standar sebesar 0,56 (56\%). Beberapa penelitian sebelumnya yang berkaitan dengan pengaruh gaya kepemimpinan terhadap kinerja yaitu Dwiantoro et al (2017) meneliti bahwa gaya kepemimpinan transformasional memiliki pengaruh positif signifikan terhadap kinerja, gaya kepemimpinan transaksional memiliki pengaruh negatif signifikan terhadap kinerja. Iswatiningsih et al. (2018) meneliti bahwa tidak ada pengaruh yang signifikan antara kepemimpinan transformasional terhadap kinerja karyawan, ada pengaruh yang signifikan antara kepemimpinan transaksional terhadap kinerja karyawan.

\section{Pengaruh gaya Kepemimpinan Transaksional (X1) Pada Sistem Jaminan Halal HAS 23000 (Y).}

Untuk gaya kepemimpinan transaksional juga berpengaruh positif dan signifikan terhadap kinerja sistem manajemen keamanan pangan dengan nilai statistik t yang diperoleh sebesar 6,60> 1,96 dengan koefisien tidak standar sebesar 0,45 (45\%). Hasil penelitian dari Rahim et al (2018) menyimpulkan bahwa kepemimpinan transformasional mempengaruhi kinerja karyawan dan kepemimpinan transaksional tidak mempengaruhi kinerja karyawan. Hidayati et al (2014) meneliti bahwa kepemimpinan transformasional mempengaruhi kinerja karyawan sedangkan 
kepemimpinan transaksional tidak berpengaruh pada kinerja karyawan. Rosnani et al (2012) kepemimpinan transaksional tidak memiliki pengaruh positif yang signifikan terhadap kinerja. Kepemimpinan transformasional memiliki pengaruh positif signifikan terhadap kepuasan kerja. Eng Sun et al. (2018) menyimpulkan bahwa gaya kepemimpinan transformasional mempengaruhi kinerja. Gaya kepemimpinan transaksional tidak berpengaruh pada kinerja. Hamidah et al (2016) kepemimpinan transformasional memiliki pengaruh negatif dan tidak signifikan terhadap kinerja karyawan dan kepemimpinan transaksional tidak berpengaruh signifikan terhadap kinerja karyawan.

Masa'deh (2016) menemukan bahwa gaya kepemimpinan transaksional dan transformasional memiliki dampak positif dan signifikan terhadap kinerja pekerjaan dan kepemimpinan transaksional memengaruhi berbagi pengetahuan, kepemimpinan transformasional tidak memengaruhi berbagi pengetahuan. Crawford et al. (2005) kepemimpinan transformasional memprediksi perilaku manajemen pengetahuan secara signifikan untuk 19,5 persen dari varians. Posisi organisasi adalah prediksi yang signifikan dari manajemen pengetahuan dengan kepemimpinan transformasional untuk 21,1 persen dari varian manajemen pengetahuan. Rao et al (2005) mengemukakan bahwa kepemimpinan transformasional memiliki dampak positif yang signifikan terhadap kinerja tim dan kepemimpinan transaksional memiliki pengaruh negatif yang signifikan terhadap kinerja tim. Erkutlu et al (2008), Ada hubungan yang signifikan antara perilaku kepemimpinan dan kepemimpinan dan efektivitas organisasi. Perilaku kepemimpinan transformasional merangsang komitmen organisasi dan kepuasan kerja dalam industri perhotelan. Hu et al. (2010) menemukan ada hubungan positif dan signifikan antara manajer kepemimpinan transformasional dan kepuasan kerja. Taylor et al (2014) kepemimpinan visioner memiliki korelasi signifikan dan positif dengan persepsi efektivitas organisasi dan korelasi signifikan antara perilaku kepemimpinan tinggi dan persepsi efektivitas organisasi.

Beberapa penelitian terdahulu dengan topik gaya kepemimpinan yang memiliki pengaruh terhadap kinerja yaitu (Dwiantoro et al, 2014) telah meneliti bahwa gaya kepemimpinan dengan tipe transformasional memiliki pengaruh positif dan signifikan terhadap kinerja. Sementara gaya kepemimpinan dengan tipe transaksional memiliki pengaruh negatif yang signifikan terhadap kinerja. Rahim et al. (2018) meneliti bahwa kepemimpinan transformasional berpengaruh terhadap kinerja karyawan dan kepemimpinan transaksional tidak berpengaruh terhadap kinerja karyawan. Isnawati et al. (2016) melakukan penelitian dan menyimpulkan bahwa gaya kepemimpinan transformasional berpengaruh terhadap kinerja. gaya kepemimpinan transaksional tidak berpengaruh terhadap kinerja. Aqmarina et al (2018) melakukan penelitian dan menyimpulkan bahwa kepemimpinan tipe transformasional berpengaruh secara negatif dan tidak signifikan terhadap kinerja karyawan sedangkan kepemimpinan 
transaksional berpengaruh secara tidak signifikan terhadap kinerja karyawan.

Wahyuniardi et al.(2014) melakukan penelitian dan menyimpulkan bahwa kepemimpinan tipe transformasional berpengaruh cukup signifikan kepada kepuasan kerja, sementara itu penelitian ini menunjukkan bahwa kepemimpinan dengan tipe transformasional tidak mempunyai pengaruh secara signifikan terhadap kinerja para karyawan, demikian pula dengan budaya organisasi yang tidak memiliki pengaruh secara signifikan terhadap kinerja karyawan. Lebih jauh lagi kepuasan kerja tidak secara signifikan terhadap kinerja karyawan. Wahyuniardi berpendapat bahwa untuk dapat meningkatkan kinerja karyawan maka yang dapat dilakukan adalah dengan cara meningkatkan kepuasan kerja jika kepuasan kerja meningkat maka kinerja karyawan akan meningkat juga Birasnav et al. (2015) juga telah melakukan penelitian tentang kepemimpinan dan hasil penelitiannya berhasil memberikan gambaran bahwa kepemimpinan dengan tipe transformasional dan juga transaksional memiliki pengaruh yang sangat kuat juga positif pada performa organisasi setelah mengendalikan efek kepemimpinan transaksional. Penelitian yang dilakukan Tsai et al ( 2015) dan Klüche et al.(2019) menyimpulkan bahwa food safety memberikan manfaat kepada perusahaan.

\section{KESIMPULAN}

Berdasarkan penelitian yang telah dilakukan dapat disimpulkan bahwa variabel gaya kepemimpinan transformasional (X1) memiliki pengaruh positif dan signifikan terhadap kinerja bisnis industri minuman (Y) dan variabel gaya kepemimpinan transaksional (X2) juga memiliki pengaruh positif dan signifikan terhadap variabel kinerja Sistem Jaminan Halal HAS 23000 (Y). Untuk manajemen industri minuman sebaiknya menggunakan gaya kepemimpinan transformasional dan transaksional karena keduanya berpengaruh positif terhadap kinerja sistem manajemen keamanan pangan, jika memperhatikan hasil penelitian, gaya kepemimpinan tipe transformasional lebih berpengaruh positif pada peningkatan kinerja sistem manajemen keamanan pangan tetapi kepemimpinan yang lebih efektif adalah kombinasi dari kedua gaya kepemimpinan.

Untuk itu pemimpin harus memperhatikan gaya kepemimpinan yang akan digunakan untuk bawahan karena gaya kepemimpinan merupakan faktor yang paling berpengaruh terhadap peningkatan kinerja sistem manajemen keamanan pangan. Untuk penelitian lebih lanjut akan meneliti pengaruh gaya kepemimpinan terhadap kinerja sistem manajemen keamanan kaum pagan dapat menambahkan beberapa variabel lain yang diduga dapat mempengaruhi kinerja sistem manajemen keamanan pangan, misalnya sebagai motivasi, kemampuan atau kompetensi individu dan budaya kerja. 


\section{DAFTAR PUSTAKA}

Ab Talib, M., Abdul Hamid, A. and Chin, T. (2016), "Can halal certification influence logistics performance?", Journal of Islamic Marketing, Vol. 7 No. 4, pp. 461-475. https://doi.org/10.1108/JIMA-02-2015-0015

Ab Talib, M., Md. Sawari, S., Abdul Hamid, A. and Ai Chin, T. (2016), "Emerging Halal food market: an Institutional Theory of Halal certificate implementation", Management Research Review, Vol. 39 No. 9, pp. 987997. https://doi.org/10.1108/MRR-06-2015-0147

Ab Talib, M., Abdul Hamid, A. and Zulfakar, M. (2015), "Halal supply chain critical success factors: a literature review", Journal of Islamic Marketing, Vol. 6 No. 1, pp. 44-71. https://doi.org/10.1108/JIMA-072013-0049

Ab Talib, M., Ai Chin, T. and Fischer, J. (2017), "Linking Halal food certification and business performance", British Food Journal, Vol. 119 No. 7, pp. 1606-1618. https://doi.org/10.1108/BFJ-01-2017-0019

Ab Talib, M. (2017), "Motivations and benefits of halal food safety certification", Journal of Islamic Marketing, Vol. 8 No. 4, pp. 605-624. https://doi.org/10.1108/JIMA-08-2015-0063

Ab Talib, M. and Ai Chin, T. (2018), "Halal food standard implementation: are Malaysian firms proactive or reactive?", British Food Journal, Vol. 120 No. 6, pp. 1330-1343. https://doi.org/10.1108/BFJ-07-2017-0366

Ali, A., Xiaoling, G., Sherwani, M. and Ali, A. (2018), "Antecedents of consumers' Halal brand purchase intention: an integrated approach", Management Decision, Vol. 56 No. 4, pp. 715-735. https://doi.org/10.1108/MD-11-2016-0785

Annabi, C. and Ibidapo-Obe, 0. (2017), "Halal certification organizations in the United Kingdom: An exploration of halal cosmetic certification", Journal of Islamic Marketing, Vol. 8 No. 1, pp. 107-126. https://doi.org/10.1108/JIMA-06-2015-0045

Asnawi, N., Sukoco, B. and Fanani, M. (2018), "Halal products consumption in international chain restaurants among global Moslem consumers", International Journal of Emerging Markets, Vol. 13 No. 5, pp. 1273-1290. https://doi.org/10.1108/IJoEM-11-2017-0495

Asbari, M., Santoso, P., \& Purwanto, A. (2019). Pengaruh Kepemimpinan dan Budaya Organisasi Terhadap Perilaku Kerja Inovatif Pada Industri 4.0. JIM UPB (Jurnal Ilmiah Manajemen Universitas Putera Batam), 8(1), 715. doi: https://doi.org/10.33884/jimupb.v8i1.1562

Asbari, M., Santoso, P., \& Purwanto, A. (2019). Pengaruh Iklim Organisasi dan Kepemimpinan Transformasional Terhadap Produktivitas Kerja Inovatif Pada Industri Manufaktur di Pati Jawa Tengah. Jurnal Produktivitas Universitas Muhammadiyah Pontianak, 7(1 2020), 62-69. doi: DOI : 10.29406/jpr.v7i1.1797

Azmi, F., Abdullah, A., Musa, H. and Wan Mahmood, W. (2019), "Perception of food manufacturers towards adoption of halal food supply chain in Malaysia: Exploratory factor analysis", Journal of Islamic Marketing, Vol. 
Evy Yanthy dkk.

ahead-of-print No. ahead-of-print. https://doi.org/10.1108/JIMA-122018-0236

Acharry, P. Boonrawd. C.Chianchana, "Evaluation Research of Integrated Productivity and Eco-friendly Development Project for Enterprise in Electrical and Electronics Industry", Procedia - Social and Behavioral Sciences, 2014;116:

2970-2975, https://doi.org/10.1016/j.sbspro.2014.01.690

ANZMAC Conference: Corporate Responsibility (2005)

Asbari, M., Santoso, P., \& Purwanto, A. (2019). Influence of Leadership, Motivation, Competence, Commitment and Culture on ISO 9001:2015 Performance in Packaging Industry, Scholars Journal of Economics, Business and Management, 6(12): 577-582. DOI: http://doi.org/10.36347/sjebm.2019.v06i12.005

Asbari, M., Santoso, P., \& Purwanto, A. (2019). Pengaruh Kepemimpinan dan Budaya Organisasi Terhadap Perilaku Kerja Inovatif Pada Industri 4.0. JIM UPB (Jurnal Ilmiah Manajemen Universitas Putera Batam), 8(1), 715. doi: https://doi.org/10.33884/jimupb.v8i1.1562

Asbari, M., Santoso, P., \& Purwanto, A. (2019). Pengaruh Iklim Organisasi dan Kepemimpinan Transformasional Terhadap Produktivitas Kerja Inovatif Pada Industri Manufaktur di Pati Jawa Tengah. Jurnal Produktivitas Universitas Muhammadiyah Pontianak, 7(1 2020), 62-69. doi: DOI : 10.29406/jpr.v7i1.1797

Bass B. M., The ethics of transformational leadership, KLSP:Transformational Leadership, Working Papers (1997)

Bass B. M., The ethics of transformational leadership, KLSP:Transformational Leadership, Working Papers (1997)

Bashir, K., Kim, J., Mohibbullah, M., Sohn, J. and Choi, J. (2019), "Strategies for improving the competitiveness of Korean seafood companies in the overseas halal food market", Journal of Islamic Marketing, Vol. 10 No. 2, pp. 606-632. https://doi.org/10.1108/JIMA-03-2018-0056

Bruce Tracey J. and Timonthy R. Hinkin, How transformational leaders lead in the hospitality industry, Internal Journal of Hospitality Management, 15(2), 165-176 (1995)

Bunmi Omolayo, Effect of Leadership Style on Job-Related Tension and Psychological Sense of Community in Work Organizations: A Case Study of Four Organizations in Lagos State, Nigeria, Bangladesh e-Journal of Sociology, 4(2), July (2007)

Bouzembrak, M. Klüche,, "Internet of Things in food safety: Literature review and a bibliometric analysis", Trends in Food Science \& Technology: 2019;94: 54-64, https://doi.org/10.1016/j.tifs.2019.11.002

C. E.María,L.S. Vijande,"Reasons and constraints to implementing an FSSC 22000 food safety management system: Evidence from Spain". Food Control Journal, 2014;40: 50-57, https://doi.org/10.1016/j.foodcont.2013.11.032 
Chung-Hsiung Fang, Sue-Ting Chang and Guan-Li Chen, Applying Structural Equation Model to Study of the Relationship Model among leadership style, satisfaction, Organization commitment and Performance in hospital industry, IEEE (2009)

Conference on Management Science \& Engineering, 15 $5^{\text {th }}$ September (2008)

Duanxu Wang, Huijuan Xue and Jie Xu, The Mechanism of Leadership Styles Affecting Team Innovation in the PRC, IEEE (2009)

De Boni, A. and Forleo, M. (2019), "Italian halal food market development: drivers and obstacles from experts' opinions", Journal of Islamic Marketing, Vol. 10 No. 4, pp. 1245-1271. https://doi.org/10.1108/JIMA05-2018-0087

Elseidi, R. (2018), "Determinants of halal purchasing intentions: evidences from UK", Journal of Islamic Marketing, Vol. 9 No. 1, pp. 167-190. https://doi.org/10.1108/JIMA-02-2016-0013

E.S.Ong, H. Ariwibowo, Isnawati, "Pengaruh Kepemimpinan Transformasional, Kepemimpinan Transaksional Dan Kebijakan Perusahaan Tentang Upah Pekerja Terhadap Produktivitas Kerja (Studi Pada PT "X" Di Surabaya)". Jurnal Jeksekutif, 2018;5: 334-335, https://jurnal.ibmt.ac.id/index.php/jeksekutif/article/view/200/168

E. Shih, T.W. Ming, C. Tsai, "Effects of the perception of traceable fresh food safety and nutrition on perceived health benefits, affective commitment, and repurchase intention", Food Quality and Preference,2019;19: https://doi.org/10.1016/j.foodqual.2019.103723

F.I.Dwiantoro,"Pengaruh Gaya Kepemimpinan Tranformasional dan Tansaksional Tehadap Kinerja Organisasi Melalui Praktik TQM Pada PT. Pelayaran". Jurnal Ilmu Manajemen, 2017; 05:1-14,

F.Rahim,V. P.K. Lengkong, L. O.H. Dotulong, "Pengaruh Kepemimpinan Transformasional Dan Kepemimpinan Transaksional Terhadap Kinerja Karyawan Pada PT. PLN Wilayah Sulutenggo". Jurnal EMBA, 2018;4: 3503 https://ejournal.unsrat.ac.id/index.php/emba/article/viewFile/21623 /21326

Firdaus, R.A.,Purnamasari, D., Akuba, S.F.(2019) The influence of motivation, leadership and perceived workload as intervening on teacher commitment. Journal of Education and Science Technology, 5(3) . DOI : https://doi.org/10.26858/est.v5i3.10847

Goh Yuan, Sheng Victor and Geoffrey N. Soutar, University of Western Australia, The Role of Ethical Behaviours In The Relations Between Leadership Styles And Job Performance,

Guang-yi Wang Zhi-sheng, The Impact of Transformational Leadership Style on Organizational Performance: The Intermediary Effects of LeaderMember Exchange, International

Ismail A., Halim F. A., Munna D. N., Abdullah A., Shminan A. S. and Muda A. L., The mediating effect of empowerment in the relationship between 
transformational leadership and service quality, J. Bus. Manage., 4(4), 312 (2009)

Hendijani Fard, M. and Seyyed Amiri, N. (2018), "The effect of entrepreneurial marketing on halal food SMEs performance", Journal of Islamic Marketing, Vol. 9 No. 3, pp. 598-620. https://doi.org/10.1108/JIMA-12-2016-0097

Howell J. M. and Avolio B. J., Transformational leadership, transactional leadership, locus of control and support for innovation: Key predictors of consolidated-business unit performance, J. Serv. Mark., 16, 487-502 (1993

https://jurnalmahasiswa.unesa.ac.id/index.php/jim/article/download/1917 $5 / 17509+\& \mathrm{~cd}=4 \& \mathrm{hl}=\mathrm{jv} \& \mathrm{ct}=\mathrm{clnk} \& \mathrm{gl}=\mathrm{id}$

https://doi.org/10.1016/S1479-8387(04)01111-7

I. F.Segovia,B. Peidro, A.Fuentes, "Implementation of a food safety management system according to FSSC 22000 in the food supplement industry: A case study", Food Control Journal,2014; 43: 28-34, https://doi.org/10.1016/j.foodcont.2014.02.042

International Standard Organization, FSSC 22000:2018 Food safety management systems - Requirements for any organization in the food chain. ISO.org, 2018; 2: https://www.iso.org/standard/65464.html

Jung D. I., Transformational and transactional leadership and their effects on creativity in groups , Creativity Research Journal, 13, 185-195 (2001)

Karia, N. (2019), "Halal logistics: practices, integration and performance of logistics service providers", Journal of Islamic Marketing, Vol. ahead-ofprint No. ahead-of-print. https://doi.org/10.1108/JIMA-08-2018-0132

Kahai S. S., Sosik J. J. and Avolio B. J., Effects of Leadership Style and Problem Structure on Work Group Process and Outcomes in an Electronic Meeting System Environment,

Khan, S., Khan, M. and Haleem, A. (2019), "Evaluation of barriers in the adoption of halal certification: a fuzzy DEMATEL approach", Journal of Modelling in Management, Vol. 14 No. 1, pp. 153-174. https://doi.org/10.1108/JM2-03-2018-0031

Khan, S., Khan, M., Haleem, A. and Jami, A. (2019), "Prioritising the risks in Halal food supply chain: an MCDM approach", Journal of Islamic Marketing, Vol. ahead-of-print No. ahead-of-print. https://doi.org/10.1108/JIMA-10-2018-0206

Khan, M., Najmi, A., Ahmed, W. and Aman, A. (2019), "The role of consumer willingness to pay for halal certification in Pakistan", Journal of Islamic Marketing, Vol. 10 No. 4, pp. 1230-1244. https://doi.org/10.1108/JIMA09-2018-0155

Khan, M., Khan, S. and Haleem, A. (2019), "Analysing barriers towards management of Halal supply chain: a BWM approach", Journal of Islamic Marketing, Vol. ahead-of-print No. ahead-of-print. https://doi.org/10.1108/JIMA-09-2018-0178 
Lu Ye, Deng Junye and Ma Yan, The Relationships between Leadership Styles and Organizational Innovation Climate, IEEE (2011)

L. Macheka, F. A. Manditsera, R.T. Ngadze, J. Mubaiwa, L. K. Nyanga, "Barriers, benefits and motivation factors for the implementation of food safety management system in the food sector in Harare Province, Zimbabwe". Food Control Journal, 2013;34: 126-131, https://doi.org/10.1016/j.foodcont.2013.04.019

M.Birasnav,"Knowledge management and organizational performance in the service industry: The role of transformational leadership beyond the effects of transactional leadership", Journal of Business Research, 2014;67:1622-1629, https://doi.org/10.1016/j.jbusres.2013.09.006

Mirayani, R., S.Williana Kusumaningsih, \& Anggaripeni Mustikasiwi. (2019). TRANSFORMATIONAL, AUTHENTIC, AND AUTHORITARIAN TYPES OF LEADERSHIP: WHICH ONE IS THE MOST INFLUENTIAL IN STAFFS' PERFORMANCE (A Study On Performance In A Religious School Setting). Dinasti International Journal of Education Management And Social Science, 1(2), 172-182. https://doi.org/10.31933/dijemss.v1i2.68

Muhamed, A., Ab Rahman, M., Mohd Hamzah, F., Che Mohd Zain, C. and Zailani, S. (2019), "The impact of consumption value on consumer behaviour: A case study of halal-certified food supplies", British Food Journal, Vol. 121 No. 11, pp. 2951-2966.

Mohd Nawawi, M., Abu-Hussin, M., Faid, M., Pauzi, N., Man, S. and Mohd Sabri, N. (2019), "The emergence of halal food industry in non-Muslim countries: a case study of Thailand", Journal of Islamic Marketing, Vol. ahead-of-print No. ahead-of-print. https://doi.org/10.1108/JIMA-052018-0082

Mohd Suki, N. and Abang Salleh, A. (2016), "Does Halal image strengthen consumer intention to patronize Halal stores? Some insights from Malaysia", Journal of Islamic Marketing, Vol. 7 No. 1, pp. 120-132. https://doi.org/10.1108/JIMA-12-2014-0079

Mullins L., Management and Organisational Behaviour,Pearson Higher Education FT Prentice Hall (2004)

Mirayani, R., S.Williana Kusumaningsih, \& Anggaripeni Mustikasiwi. (2019). TRANSFORMATIONAL AUTHENTIC, AND AUTHORITARIAN TYPES OF LEADERSHIP: WHICH ONE IS THE MOST INFLUENTIAL IN STAFFS' PERFORMANCE (A Study On Performance In A Religious School Setting). Dinasti International Journal of Education Management And Social Science, 1(2), 172-182. https://doi.org/10.31933/dijemss.v1i2.68

N.S. Aqmarina, H.N. Utami, A. Prasetya," Pengaruh Kepemimpinan Transformasional Dan Kepemimpinan Transaksional Terhadap Kepuasan Kerja Dan Kinerja Karyawan ( Studi Kasus Pada Karyawan Hotel Gajah Mada Malang)". Jurnal Administrasi Bisnis,2016;35:164-173, 
http://administrasibisnis.studentjournal.ub.ac.id/index.php/jab/article /view/1382

N. Cavusoglu, "LISREL growth model on direct and indirect effects using cross-country data," Economic Modelling, 2012;29; 2362-2370, https://doi.org/10.1016/j.econmod.2012.05.025

Naeem, S., Ayyub, R., Ishaq, I., Sadiq, S. and Mahmood, T. (2019), "Systematic literature review of halal food consumption-qualitative research era 1990-2017", Journal of Islamic Marketing, Vol. ahead-of-print No. aheadof-print. https://doi.org/10.1108/JIMA-09-2018-0163

Ngah, A., Zainuddin, Y. and Thurasamy, R. (2015), "Barriers and enablers in adopting of Halal warehousing", Journal of Islamic Marketing, Vol. 6 No. 3, pp. 354-376. https://doi.org/10.1108/JIMA-03-2014-0027

Omar, N., Zainol, Z., Thye, C., Ahmad Nordin, N. and Nazri, M. (2017), "Halal violation episode: does severity and trust recovery impact negative consumption behavior?", Journal of Islamic Marketing, Vol. 8 No. 4, pp. 686-710. https://doi.org/10.1108/JIMA-10-2015-0081

Othman, B., Shaarani, S. and Bahron, A. (2016), "Evaluation of knowledge, halal quality assurance practices and commitment among food industries in Malaysia", British Food Journal, Vol. 118 No. 8, pp. 20332052. https://doi.org/10.1108/BFJ-12-2015-0496

Othman, B., Md. Shaarani, S. and Bahron, A. (2017), "The influence of knowledge, attitude and sensitivity to government policies in halal certification process on organizational performance", Journal of Islamic Marketing, Vol. 8 No. 3, pp. 393-408. https://doi.org/10.1108/JIMA-092015-0067

O. Boe, "Using LISREL V to Perform a Covariance Structure Analysis of a Tripartite Model of Attitude", Procedia - Social and Behavioral Sciences, 2015;182: 360-363, https://doi.org/10.1016/j.sbspro.2015.04.786

Prabowo, S., Abd Rahman, A., Ab Rahman, S. and Samah, A. (2015), "Revealing factors hindering halal certification in East Kalimantan Indonesia", Journal of Islamic Marketing, Vol. 6 No. 2, pp. 268-291. https://doi.org/10.1108/JIMA-05-2014-0040

Purwanto, A.,Hutagalung,L.,Yanthy,.E.,(2020). FOOD SAFETY MANAGEMENT LEADERSHIP STYLE: TRANSFORMATIONAL OR TRANSACTIONAL?. Jurnal Ekonomi 182.https://doi.org/10.30650/jem.v14i1.1288 Manajemen.14(2).171-

Purwanto, A., Asbari, M., \& Santoso, P.(2019).Pengaruh Kompetensi, Motivasi, Kepemimpinan, Komitmen dan Budaya Kerja Sistem Manajemen Integrasi ISO 9001, ISO 14000 dan ISO 45001 Pada Industri Otomotif. Jurnal Produktivitas Universitas Muhammadiyah Pontianak, 6(2),158166. DOI: http://dx.doi.org/10.29406/jpr.v6i2.1798

Purwanto, A., Asbari, M., \& Santoso, P.(2019).Influence of Transformational and Transactional Leadership Style toward Food Safety Management System ISO 22000:2018 Performance of Food Industry in Pati Central 
Java. Jurnal Inovasi Bisnis, 6(2), 180-185. DOI: https://doi.org/10.35314/inovbiz.v7i2.1213

Purwanto, A., Asbari, M., \& Santoso, P.(2019). Does Culture, Motivation, Competence, Leadership,Commitment Influence Quality Performance?. Jurnal Inovasi Bisnis, 6(2), 201-205. DOI: https://doi.org/10.35314/inovbiz.v7i2.1210

Purwanto, A., Wijayanti, L.M., Hyun, C.C., Asbari, M. (2020). The Effects of Transformational, Transactional, authentic, Authoritarian Leadership style Toward Lecture Performance of Private University in Tangerang. Dinasti International Journal of Digital Business Management (DIJDBM), 1(1), 29-42.DOI:https://doi.org/10.31933/dijdbm.v1i1.88

Purwanto, A. ,Bernarto, I.,Asbari, M., Wijayanti, L.M., Hyun,C.C, (2020) THE IMPACTS OF LEADERSHIP AND CULTURE ON WORK PERFORMANCE IN SERVICE COMPANY AND INNOVATIVE WORK BEHAVIOR AS MEDIATING EFFECTS , Journal of Research in Bussiness, Economics, and Education, 2(1)

Purwanto, A. ,Bernarto, I.,Asbari, M., Wijayanti, L.M., Hyun,C.C, (2020) EFFECT OF TRANSFORMATIONAL AND TRANSACTIONAL LEADERSHIP STYLE ON PUBLIC HEALTH CENTRE PERFORMANCE, Journal of Research in Bussiness, Economics, and Education, 2(1), 304-314.

Purwanto, A., Asbari, M., \& Santoso, P.(2019).Influence of Transformational and Transactional Leadership Style toward Food Safety Management System ISO 22000:2018 Performance of Food Industry in Pati Central Java. Jurnal Inovasi Bisnis, 6(2), 180-185. DOI: https://doi.org/10.35314/inovbiz.v7i2.1213

PURWANTO, A., Primahendra, R., Sopa, A., Kusumaningsih, S., \& Pramono, R. (2020). Pengaruh Gaya Kepemimpinan Tansformational, Authentic,Authoritarian, Transactional Terhadap Kinerja Guru Madrasah Aliyah di Tangerang. EVALUASI: Jurnal Manajemen Pendidikan Islam, 20-44. doi:http://dx.doi.org/10.32478/evaluasi.v4i1.342

Purwanto, A., Asbari, M., Prameswari, M., \& Ramdan, M. (2020). GAYA KEPEMIMPINAN DI MADRASAH ALIYAH: AUTHENTIC, TANSFORMATIONAL, AUTHORITARIAN ATAU TRANSACTIONAL?. Nidhomul Haq : Jurnal Manajemen Pendidikan Islam, 5(1), 16-31. https://doi.org/10.31538/ndh.v5i1.544

Purwanto,A.,Asbari,M.(2020).Pengaruh Gaya Kepemimpinan Tansformational, Authentic, Authoritarian, Transactional terhadap Kinerja Guru Pesantren di Tangerang. DIRASAH. 3(1).85-110. https://doi.org/10.29062/dirasah.v3i1.84

P. Ebrahimi, S. M. Moosavi, E. Chirani, "Relationship between Leadership Styles and Organizational Performance by Considering Innovation in Manufacturing Companies of Guilan Provin", Procedia - Social and Behavioral Sciences, 2016;230: 351-358, https://doi.org/10.1016/j.sbspro.2016.09.044 
Evy Yanthy dkk.

Podsakoff P. M., MacKenzie S. B., Moorman R. H. and Fetter R., Transformational leader behaviors and their effects on followers" trust in leader, satisfaction and organizational citizenship behaviors, Leadership Quarterly, 1, 107-142 (1990)

Podsakoff P. M., MacKenzie S. B., Moorman R. H. and Fetter R., Transformational leader behaviors and their effects on followers" trust in leader, satisfaction and organizational citizenship behaviors, Leadership Quarterly, 1, 107-142 (1990)

Pelu, MIEA. 2009. Label Halal: Antara Spiritualitas Bisnis dan Komoditas Agama (Malang: Madani, 2009), h. 31-55.

Qijun, P. J.Batt, "Barriers and benefits to the adoption of a third party certified food safety management system in the food processing sector in Shanghai, China", Food Control,2016;62: 89-96, https://doi.org/10.1016/j.foodcont.2015.10.020

Quoquab, F., Mohamed Sadom, N. and Mohammad, J. (2019), "Driving customer loyalty in the Malaysian fast food industry: The role of halal logo, trust and perceived reputation", Journal of Islamic Marketing, Vol. ahead-of-print No. ahead-of-print. https://doi.org/10.1108/JIMA-012019-0010

Rahim, N. (2016), "Consumer Behaviour, Perception and Planning Towards Halal Marketing", Mutum, D., Butt, M. and Rashid, M. (Ed.) Advances in Islamic Finance, Marketing, and Management, Emerald Group Publishing Limited, pp. 271-307. https://doi.org/10.1108

Rahman, F., Tareq, M., Yunanda, R. and Mahdzir, A. (2017), "Maqashid AlShari'ah-based performance measurement for the halal industry", Humanomics, Vol. 33 No. 3, pp. 357-370. https://doi.org/10.1108/H-032017-0054

R. Wahyuniardi, H.R. Nababan,"Pengaruh Kepemimpinan Transformasional Dan Budaya Organisasi Terhadap Kepuasan Kerja Serta Dampaknya Pada Kinerja Karyawan",Jurnal Teknik Industri, 2018;19:118-226, https://doi.org/10.22219/JTIUMM.Vol19.No2.118-126

Santoso, P, Purwanto, A., \& Asbari, M.(2019). Influence of Implementation Chain of Custody Forest Management System FSC-STD-40-004 V3-0 to Business Performance of Paper Industriesia in Banten Indonesia, International Journal of Management and Humanities (IJMH), 4(4), 3236. DOI: https://doi.org/10.35940/ijmh.C0442D0482.124419

Sharma B. R., Not by bread alone - A study of employer - employee relations in India, New Delhi, Shri Ram Centre for Industrial Relations and Human Resources (1987)

Voon M. C. et al, The influence of leadership styles on employees" job satisfaction in public sector organizations in Malaysia, International Journal of Business, Management and Social Sciences, 2(1), 24-32 (2011) 
Wiguna, R.IIsmail, "Validation study of Indonesian mother-infant bonding scale", Asian Journal of Psychiatry, 2019;43: 60-64, https://doi.org/10.1016/j.ajp.2019.05.003

Williams, Gavin, "Structural Equation Modeling Methodes In Srategy Research : Application and Issue" Research Methodology in Strategy and Management (Research Methodology in Strategy and Management, Vol. 1), Emerald Group Publishing Limited, Bingley,2004 ; pp. 303-346.

Yang Jen-Te, Knowledge sharing: Investigating appropriate leadership roles and collaborative culture, Tourism Management, 28, 530-543 (2007) Personnel Psychology, 50, 1-146 (1997) 